\title{
Spiritual motivation, work culture and work ethos as predictors on merchant satisfaction through service quality of street vendors in Badung market, Bali, Indonesia
}

\author{
Chablullah Wibisono $^{a^{*}}$ and I Wayan Catrayasa ${ }^{b}$
}

${ }^{a, b}$ Faculty of Economics, University of Batam, Indonesia

CHRON I C L E A B S T R A C T

Article history:

Received: November 26, 2017

Received in revised format:

March 31, 2018

Accepted: April 4, 2018

Available online:

April 5, 2018

Keywords:

Spiritual Motivation

Work Culture and Work Ethos

Quality Service

Merchants Satisfaction

\begin{abstract}
The real growth of the economy of street vendors in Badung Market, Bali has been increasing rapidly from year to year. Based on spiritual motivation, work culture and work ethos, and supported by the level of service quality and customer satisfaction, the research was conducted in relation to spiritual motivation, work culture and work ethos as predictors of merchant satisfaction through service quality of street vendors in Badung market. The population of the research was the entire street vendors in Badung Market. The numbers of qualified sample were 140 respondents. The variable measurement was conducted by using the Likert scale. The study used the structural equation modeling (SEM) for model analysis. The results showed that the effect of spiritual Motivation variable on Service Quality variable was significant and positive. The effect of work Culture variable on Service Quality variable is significant positive. The effect of Work Ethos variable on Service Quality variable is significant and positive. Spiritual Motivation latent variable on Merchants Satisfaction variable is significant and positive. The effect of Work Culture variable on Merchants Satisfaction variable is significant and positive. The effect of Work Ethic variable on Merchants Satisfaction variable is significant and positive. The effect of Service Quality variable on Merchants Satisfaction variable is significant and positive. Thus, It can be stated that the merchant satisfaction changes are affected by spiritual motivation, work culture, work ethos and that the street vendor improve service quality.
\end{abstract}

\section{Introduction}

The real growth of the economy of street vendors in the Badung Market, Bali showed considerable potential numbers of data increasing from year to year. The increase in the number of merchants in line with rising levels of income gives colors to characteristics of street vendors. Denpasar is a trade city in Bali that is quite well known in this country considering that it is the place visited by domestic and international tourists where the positive compensation for most of the people are as business owners and workers in the informal sectors. One of the informal sector existing is street vendors. On the basis of spiritual motivation, work culture and work ethos, and encouraged by the level of service quality and customer satisfaction (Nawaz et al., 2017), the research is conducted in relation to spiritual motivation, work culture and work ethos as predictors of merchant satisfaction through service quality of street vendors in the market. 
On the basis of the description above, the research problem can be formulated as the following formulation: 1) Is spiritual motivation the predictor of service quality? 2) Is the work culture the predictor of service quality? 3) Is the work ethos the predictor of service quality? 4) Are spiritual motivation, work culture and work ethos simultaneously predictors of service quality? 5) Is spiritual motivation direct predictor of customer satisfaction? 6) Is work culture a direct predictor of customer satisfaction? 7) Is work ethos a direct predictor of customer satisfaction? 8) Is spiritual motivation, work culture and work ethic direct predictors of customer satisfaction? 9) Is service quality the predictor of customer satisfaction?

\section{Literature Review}

\subsection{Spiritual Motivation Concept}

Spiritual motivation is the driving force that generates activity in living beings, and promotes behavior and directs it towards a specific purpose. Spiritual need is an innate need that the fulfillment of the need depends on the perfection of personal growth and maturity of the individual. The fulfillment of the spiritual need highly affects the formation of self-concept, which in turn will manifest in a person's behavior.

\subsection{Work Culture}

Literally, the word culture is originated from the Latin word Colere, which means till the soil, cultivate and maintain a field. The definition and understanding of culture have been shifted to be more applied to things that are spiritual. Culture as a particular way of life exudes a certain identity of a nation as well. According to Koentjaraningrat (2004) "culture is a whole system of ideas and the work of human actions in the context of a society that is obtained by human beings by learning". Furthermore, it is stated that culture has three states namely first, the form of culture as a complexity of ideas, values, norms, regulations and so on, second, the form of culture as a complexity of pattern behavior activity of human in society, and third, the form of culture as objects of human work

\subsection{Work Ethos}

According to Tamara (2002), the characteristics of work ethos are (1) on time, (2) morality, (3) honesty, (4) commitment, (5) strong stance, (6) discipline, (7) responsibility, (8) confidence, (9) creative. Based on these characteristics the following can be concluded as indicators of the work ethos:

(1) On time. That is a behavior that obeys the binding provisions of time in carrying out the work and understands and knows that time is precious to achieve the goals set.

(2) Responsibility. There are three aspects of responsibilities (a) responsibility as an obligation that must be done, (b) responsibility for determining obligation, (c) responsibility as authority.

(3) Honesty. Tasmara (2002) states that honest with ourselves also means seriousness to improve and develop the mission and existence mode. To provide the highest for others, reveal itself as a true, simple, righteous and clean as well as authentic person and realize that existence is only meaningful if it gives benefit to others truly without falsehood to hide or manipulate the facts.

(4) Confidence. Self-confidence appears when the inner power of an individual serves well. Confident not only requires awareness of the value and awareness to control the will but it also needs to be free from obstructions such as mood, feelings of inferiority, and free from self-emotions.

\subsection{Service Quality}

Parasuraman et al. (1988) conducted a research on some types of service quality and managed to identify the characteristics of the five dimensions which are frequently used by customers in evaluating the quality of the service. The five dimensions are reliability, responsiveness, assurance, and tangible. 
Reliability is the capability to provide services quickly and satisfactorily in line with something that has been assured. The willingness to help customers and provide services with the response is called responsiveness, while the ability, the courtesy, and the trustworthiness of the employee and staff including the freedom from danger, risk or hesitations is called assurance (Qureshi et al., 2014). Empathy includes easiness in the relationship, high quality of communication, and consideration to customer needs. Tangibles include the physical facilities, equipment, employees, and communication facilities.

\subsection{Customer Satisfaction}

There are five main factors used as indicators and need to be considered in relation to customer satisfaction, among others are Product Quality, Service Quality, Emotional, Price, and Cost. Customers will be satisfied if the assessment showed that the product that they use qualified (Dawi et al., 2016; Qureshi et al., 2012). The product is considered qualified for someone if the product can meet the needs. Product quality is composed of two kinds, namely external and internal, one of the external factor of the quality of the product is the brand image (Amegbe et al., 2017). Customers will be satisfied if they get a good or service that is in line with expectations. Consumers feel satisfied when people praise him for using an expensive brand. A product that has the same quality but set a relatively cheap price would give a higher value. Customers who do not need to spend additional costs or do not need to waste time to get products or services tend to be satisfied with the products or services. Based on the description above then the factors that affect customers satisfaction are one such product quality. The product quality is said when fulfilled customer expectations based on actual performance products.

\subsection{Framework of thinking}

The study uses correlation and regression analysis in which the three independent variables (X1, X2, $\mathrm{X} 3$ ) are connected to the dependent variables (Y1) and (Y2) with a pattern of relationships: (1) the relationship between the variables $\mathrm{X} 1$ to the variables (Y1) and (Y2), (2) the relationship between the variables $\mathrm{X} 2$ to variable (Y1) and $\left(\mathrm{Y}_{2}\right)$, and (3) the relationship between the variables $\mathrm{X}_{3}$ to the variables $\left(\mathrm{Y}_{1}\right)$ and $\left(\mathrm{Y}_{2}\right)$, and the relationship between the variables $\mathrm{X}_{1}, \mathrm{X}_{2}$ and $\mathrm{X}_{3}$ together -Same with the variables $\left(\mathrm{Y}_{1}\right)$ and $\left(\mathrm{Y}_{2}\right)$.

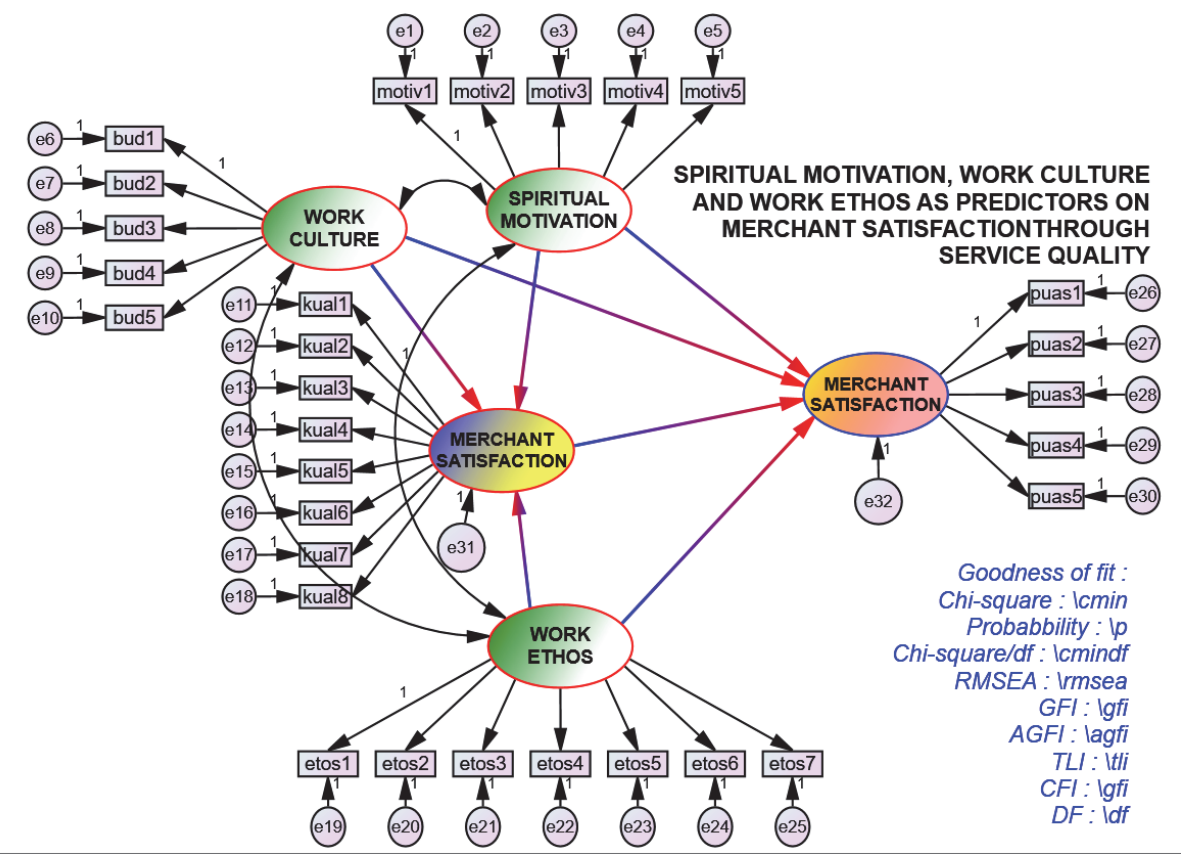

Fig. 1. Spiritual Motivation, Work Culture, and Work Ethos as Predictors On Merchant Satisfaction Through Service Quality of Street Vendors in Badung Market, Bali, Indonesia

From that model, it can be hypothesized that the research developed as follows:

H1: Spiritual motivation affects the service quality. 
$\mathrm{H} 2$ : Work culture affects the service quality.

H3: Work ethos affects the service quality.

H4: Spiritual motivation, work culture, and work ethic affect collectively the service quality.

H5: Spiritual motivation directly affects the customer satisfaction.

H6: Work culture directly affects the customer satisfaction.

H7: Work ethos directly affects customer satisfaction.

H8: Spiritual motivation, work culture, and work ethic affect collectively and directly customer satisfaction.

H9: Quality service affects customer satisfaction either directly or indirectly.

In accordance with the analysis model used in this research that is structural equation modeling (SEM), the variables used include exogenous variables, indicators (measured variables/observed variables) and endogenous (Ferdinand, 2002). According to Hair et al. (1998) and Ferdinand (2002) Exogenous variable is a source of variables or independent variable not predicted by other variables in a model. 2) Endogenous variable is an outcome variable or dependent variable of at least one causality in a model. 3) Indicator is a measured variable used to measure the concept (exogenous and endogenous) that can not be measured directly. In this research, the exogenous variables are spiritual motivation, work culture and work ethos. The endogenous variables are service quality and customer satisfaction. The operational definition of exogenous variables, endogenous variables and indicators as shown in Table 1.

Table 1

Definition of research variable operation

\begin{tabular}{llll}
\hline \multicolumn{1}{c}{ Constructions } & \multicolumn{1}{c}{ Indicators } & Kode & Sumber \\
\hline \multirow{3}{*}{ Spiritual Motivation } & Internal & $\mathrm{X}_{1}$ & Abdurrahman (2004:140) \\
\hline \multirow{2}{*}{ Work Culture } & External & $\mathrm{X}_{2}$ & \\
& Work Attitude & $\mathrm{X}_{3}$ & (Koentjaraningrat, 2004) \\
& Work Behavior & $\mathrm{X}_{4}$ & \\
\hline \multirow{3}{*}{ Work Ethos } & Punctuality & $\mathrm{X}_{5}$ & Tamara (2002:73) \\
& Responsibility & $\mathrm{X}_{6}$ & \\
& Honesty & $\mathrm{X}_{7}$ & \\
& Self Confidence & $\mathrm{X}_{8}$ & \\
\hline \multirow{3}{*}{ Service Quality } & Tangible & $\mathrm{X}_{9}$ & Zeithaml, Berry dan Prasuraman (in \\
& Empathy & $\mathrm{X}_{10}$ & Zulian Yamit, 2005:10-12) \\
& Responsiveness & $\mathrm{X}_{11}$ & \\
& Reliability & $\mathrm{X}_{12}$ & \\
& Assurance & $\mathrm{X}_{13}$ & \\
\hline \multirow{3}{*}{ Customer Satisfaction } & Product Quality & $\mathrm{X}_{14}$ & \multirow{2}{*}{ (Lupiyodi, 2001) } \\
& Service Quality & $\mathrm{X}_{15}$ & \\
& Emotion & $\mathrm{X}_{16}$ & \\
& Price & $\mathrm{X}_{17}$ & \\
& Cost & $\mathrm{X}_{18}$ & \\
\hline
\end{tabular}

\section{Research methodology}

\subsection{Population}

According to Donald and Pamela (2003), A population is the whole objects to be measured in the study (Cooper \& Schindler, 2003: 179). The population used by the researchers in this research is the entire street vendors in the Market of Badung, Bali. Therefore, the size of the population in this research is unknown so that the sampling technique used in the category is non-probability sampling (Donald \& Pamela, 2003; Sekaran, 2000). In accordance with the specific sample, the characteristics of the entire workers, the sampling non-probability technique selected are judgmental (purposive). This technique is selected to ensure that only the samples that have certain elements that have been established by researchers will be taken as samples (Sekaran, 2000). 


\subsection{Sample}

Donald and Pamela (2003) define samples as population elements selected to represent the population in the research. The sample size used is adapted to the analysis model used that is Structural Equation Model (SEM).

Hair et al. (1998) state that the sample size for SEM that uses the maximum likelihood estimation (MLE) model is 100-200 samples (Hair et al., 1998), five to ten times the number of parameters that has been estimated (Ferdinand, 2002). The numbers of respondents obtained in the research are 200 respondents. The numbers qualified to be used as a sample are 140 respondents.

\subsection{Research Instrument}

Questionnaire is the primary instrument to collect the data, while the variable measurement was conducted by using the Likert scale. There are two ways on how to answer the questionnaires first, the respondents were questioned about the common things that would be used to measure and whether the respondents included in the criteria. Second, the respondents were questioned whether they agree or disagree with the statements written in the questionnaire. There are five options of the answer namely: Strongly Disagree (STS), Disagree (TS), Doubtful (RR), Agree (S), and Strongly Agree (SS). Scoring. The score range is from 1 to 5. For the SS or strongly agree, the score is 5 and for the STS of strongly disagree, the score is 1 .

Table 2

Score quality of respondents' answers

\begin{tabular}{lcc}
\hline & Answer & Score \\
\hline Strongly Agree & 5 \\
Agree & 4 \\
Doubtful & 3 \\
Disagree & 2 \\
Strongly disagree & 1 \\
\hline
\end{tabular}

\subsection{Data Collection Procedure}

The data used in this research consist of primary data and secondary data. Primary data is data obtained directly from the object of research that is by sending questionnaires directly to potential respondents.

\subsubsection{Validity and Reliability}

Criteria for validity testing is to compare recount to $r$ table, at the significant level of $95 \%$ or $\alpha=5 \%$. The item in question is valid if the questions have $r_{\text {count }}>r_{\text {standard }}=0.30$. In this case, $r_{\text {count }}$ for every item in question is the product moment correlation coefficient of each item score. The total score of all items is denoted by Corrected Item-Total Correlations on the calculation results of SPSS for each question of the variable. Meanwhile, to test the reliability of the question list from the research variables, Cronbach's Alpha coefficient is used. The Cronbach's Alpha coefficient value indicates the reliability level of the question. A variable construct said to be reliable if it has Cronbach's value $>$ than 0.60. The calculation of product moment correlation and Cronbach's Alpha coefficient is performed by using SPSS for Windows version 20.0 Special sub-menu in the menu Analyze Scale. The calculation result of the correlation coefficient of Corrected Item-Total Correlation and Cronbach's Alpha coefficients showed all indicators variable in Questionnaire are declared valid and reliable.

\section{Results and Findings}

The market of Badung Bali - One of the biggest single markets is located in the busy trading location on Jalan Gajah Made, Denpasar. Based on the data collected, the analysis of Full Model Structural Equation Modelling (SEM) was conducted. For the purpose of the analysis, we first display the figure of the processing result of Structural Equation Modelling. The hypotheses of Spiritual Motivation structural equations (X1), Work Culture (X2), Work Ethics (X3), Quality of Service (Y) and Satisfaction Traders $(Z)$ are as the following equations. 
$\mathrm{H} 1: \mathrm{Y}=\gamma_{\mathrm{y} . \mathrm{x} 1} \mathrm{X} 1+\mathrm{e} 1, \rightarrow \mathrm{X} 1$ influences directly on $\mathrm{Y}$,

$\mathrm{H} 2: \mathrm{Y}=\gamma_{\mathrm{y} . \mathrm{x} 2 \mathrm{X} 2}+\mathrm{e} 1, \rightarrow \mathrm{X} 2$ influences directly on $\mathrm{Y}$,

$\mathrm{H} 3: \mathrm{Y}=\gamma_{\mathrm{y} . \mathrm{x} 3} \mathrm{X} 3+\mathrm{e} 1, \rightarrow \mathrm{X} 3$ influences directly on $\mathrm{Y}$,

$\mathrm{H} 4: \mathrm{Y}=\gamma_{\mathrm{yx} 1} \mathrm{X} 1+\gamma_{\mathrm{yx} 2} \mathrm{X} 1+\gamma_{\mathrm{yx} 3} \mathrm{X} 3+\mathrm{e} 1, \rightarrow \mathrm{X} 1, \mathrm{X} 2, \mathrm{X} 3$ influence directly on $\mathrm{Y}$,

$\mathrm{H} 5: \mathrm{Z}=\gamma_{\mathrm{z} . \mathrm{x} 1} \mathrm{X} 1+\mathrm{e} 2, \rightarrow \mathrm{X} 1$ influences directly on $\mathrm{Z}$,

H6: $Z=\gamma_{z . x 2} X 2+e 2, \rightarrow X 2$ influences directly on $Z$,

$\mathrm{H} 7: \mathrm{Z}=\gamma_{\mathrm{z.x3}} \mathrm{X} 3+\mathrm{e} 2, \rightarrow \mathrm{X} 3$ influences directly on $\mathrm{Z}$,

H8: $Z=\gamma_{z . x 1} X 1+\gamma_{z . x 2} X 2+\gamma_{z . x 3} X 3+e 2, \rightarrow$ directly influence on $X 1, X 2, X 3$ thd $Z$,

$\mathrm{H} 9: \mathrm{Z}=\beta \mathrm{ZY} \mathrm{Y} 1+\mathrm{e} 2, \rightarrow$ directly influences on $\mathrm{Y}$ to $\mathrm{Z}$



Fig. 2. Spiritual Motivation, Work Culture, Work Ethos, Service Quality and Merchant Satisfaction

Model testing was performed using the regression coefficients for the variables Motivation Spiritual (X1), Work Culture (X2), Work Ethics (X3), Quality of Service (Y) and Satisfaction Traders (Z) through tables output from the sub-menu view/set as specified in Appendix 14. Based on the calculation of regression coefficient (regression weight) that can be found in Appendix 14 can be created output table as presented in Table 5:16 below.

Table 3

Standardized Direct Effects

\begin{tabular}{lccccr}
\hline & BUD & ETHOS & Motiv & Qual & SATISFIED \\
\hline Qual &, 356 &, 250 &, 271 &, 000 &, 000 \\
SATISFIED &, 298 &, 302 &, 187 &, 210 &, 000 \\
\hline Spiritual Motivation (KOM), Work Culture (PROF), Work Ethics (BUD), Quality of Service (MOT) and & Merchant Satisfaction (KIN) &
\end{tabular}

\section{Table 4}

The results of regression analysis

\begin{tabular}{lllllll}
\hline & & & estimate & SE & CR & P \\
\hline Qual & $\leftarrow$ & ETHOS &, 299 &, 119 & 2,516 &, 012 par_5 \\
Qual & $\leftarrow$ & Motiv &, 258 &, 096 & 2.686 &, 007 par_6 \\
Qual & $\leftarrow$ & BUD &, 386 &, 108 & 3.574 & $* * *$ par_32 \\
SATISFIED & $\leftarrow$ & Motiv &, 168 &, 085 & 2,170 &, 049 par_1 \\
SATISFIED & $\leftarrow$ & Qual &, 197 &, 097 & 2.025 &, 043 par_2 \\
SATISFIED & $\leftarrow$ & ETHOS &, 338 &, 106 & 3.181 & .001 par_3 \\
SATISFIED & $\leftarrow$ & BUD &, 303 &, 099 & 3,057 & .002 par_4 \\
\hline
\end{tabular}

Weight Spiritual Motivation (KOM), Work Culture (PROF), Work Ethics (BUD), Quality of Service (MOT) and Merchant Satisfaction (KIN) 
Table 5

Regression standardized

\begin{tabular}{lllc}
\hline & & & estimate \\
\hline Qual & $\leftarrow$ & ETHOS &, 250 \\
Qual & $\leftarrow$ & Motiv &, 271 \\
Qual & $\leftarrow$ & BUD &, 356 \\
SATISFIED & $\leftarrow$ & Motiv &, 187 \\
SATISFIED & $\leftarrow$ & Qual &, 210 \\
SATISFIED & $\leftarrow$ & ETHOS &, 302 \\
SATISFIED & $\leftarrow$ & BUD &, 298 \\
\hline Weight Spiritual Motivation (KOM), Work Culture (PROF), Work Ethics (BUD), Quality of Service (MOT) and Merchant Satisfaction (KIN)
\end{tabular}

The three tables above show the effect of Motivation Spiritual (Motiv) variable on the Quality of Service (Qual) variable which has regression weight of 0.271 , Critical ratio or the t-test value of 2.686 and probability of 0.007 . The $\mathrm{CR}$ value that is greater than 2.000 and the probability that is smaller than 0.05 indicate that the Spiritual Motivation (motive) variable influences positively on the Quality of Service (Qual). These findings are supported by Shah (1995) who found significant motivational power supplier (energizer) to behave as directed. Motivation is seen as a general term that indicates the arrangement of individual behavior wherever needed or urged from within and incentives of an environment that encourage individuals to satisfy their needs or to strive towards achieving the desired objectives.

The effect of Work Culture latent variable (BUD) to the Quality of Service variable (Qual) has regression weight of 0.356 , with the critical ratio or the t-test value 3.574 and the probability ***. The $\mathrm{CR}$ value that is greater than 2.000 and the probability that is smaller than 0.05 indicate that the work culture (BUD) effect on the Quality of Service (Qual) is significant and positive. Supporting these findings, according to Koentjaraningrat (2004), culture is a whole system of ideas and the work of human actions in the framework of a society that is obtained by human beings by learning.

Work Ethic (ETHOS) variable effect on the Quality of Service (Qual) variable has regression weight of 0.250 , Critical ratio or the t-test value of 2.516 with the probability of 0.012 . The CR value that is greater than 2.000 and the probability that is smaller than 0.05 indicate that Work Ethic (ETHOS) variable effect on the Quality of Service (Qual) is significant and positive. These findings support the theory of Sinamo (2009) stating that work ethic means all human activities that direct the energies of biological, psychological, spiritual in order to obtain certain results. Sinamo (2009) also states that work ethic is a set of positive behavior that was born as the fruit of a fundamental belief and total commitment to a set of integral work paradigm.

Due to the effect of motivation Spiritual (Motiv) to the Quality of Service (Qual) is positive and significant, the effect of Work Culture (BUD) to the Quality of Service (Qual) is positive and significant and the effect of Work Ethics (ETHOS) to the Quality of Service (Qual) is positive and significant, the simultaneous effects of Spiritual Motivation (motive), Work Culture (BUD), Work Ethics (eTHOS) to the Quality of Service (Qual) are significant and positive. This is another view of the quality of this service, which is more emphasizing on customers, the quality, and the levels. The excellent service to customers and the level of service quality is the best way to bring together consistent consumer expectations (external service standards and fees) and the performance of the system service (internal service standards, cost, and profit). For companies that are engaged in the service, company's quality of service is needed for customer satisfaction.

The Tables 3-5 show the effect of Motivation Spiritual (Motiv) variable on the merchant Satisfaction (SATISFIED) variable which has regression weight of 0.187 , Critical ratio or the t-test value of 2.190 and with the probability of 0.049 . The CR value that is greater than 2.000 and the probability that is smaller than 0.05 indicate that the Spiritual Motivation (motive) effect on the Quality of Service (Qual) is significant and positive. 
The effect of Work Culture (BUD) variable on the merchant satisfaction variable (SATISFIED) has regression weight of 0.298 , Critical ratio or the t-test value of 3.057 and with probability of 0.002 . The $\mathrm{CR}$ value that is greater than 2.000 and the probability that is smaller than 0.05 indicate that the effect of Work Culture (BUD) on the merchant satisfaction (SATISFIED) is significant and positive. Work culture reflected in work behaviors among others are hard work, perseverance, discipline, productive, responsibility, motivation, creative, dynamic, consistent, consistent, responsive, and independent. Work culture can be seen from the attitude towards work, the favoring of employment compared with other activities, such as recreation or solely derive satisfaction from a busy work themselves or feel forced to do something just for survival

The effect of Work Ethic (ETHOS) variable on Merchant Satisfaction (SATISFIED) variable has regression weight of 0.302 , critical ratio or the t-test value of 3.181 and with the probability of 0.001 . The CR value that is greater than 2.000 and the probability that is smaller than 0.05 indicate that the effect of Work Ethic (ETHOS) on Merchant Satisfaction (SATISFIED) is significant and positive.The work ethic is something unseen that affects thoughts, feelings, conversations and human action in a field of work. Beside ways of thinking, acting, and behaving, the environment is also affected by the work ethic, The work ethic is able to increase productivity, motivation, discipline, and a strong passion or enthusiasm for doing something as optimal as possible in order to achieve a quality of work as perfectly as possible.

Due to the effect of spiritual motivation (Motiv) on merchant satisfaction (SATISFIED) is positive and significant and the effect of Work Culture (BUD) to the merchant satisfaction (SATISFIED) is positive and significant, as well as the effect of work ethic (ETHOS) on merchant satisfaction (SATISFIED) is and significant, it can be stated that the effect of Spiritual Motivation (motive), Work Culture (BUD), Work Ethics (eTHOS) on merchant satisfaction (SATISFIED) is significant and positive. Based on the various opinions expressed by the experts, it can be summarized the definition of customer satisfaction is the response of the behavior exhibited by the customer by comparing the perceived performance or results to expectations. If the result is felt below expectations, then the customer will be disappointed, not satisfied or even dissatisfied, but otherwise will give the opposite result.

Table 6

Top Model Comparison with the Modified-1

\begin{tabular}{|c|c|c|c|c|}
\hline Goodness of Fit Index & Cut-of Value & Top Model & Model Modified-1 & Remarks \\
\hline Chi-square $\left(\chi^{2}\right)$ & expected small & 746.146 & 522.486 & Better \\
\hline Chi-square Relatitive ( $\chi^{2} / \mathrm{Df}$ ) & $\leq 3.00$ & $1,889 *)$ & $1,375 *)$ & Better \\
\hline Probability & $>0.05$ & 0,000 & 0,000 & Not good \\
\hline RMSEA & $\leq 0.08$ & $0,094+)$ & $0.061 *)$ & Better \\
\hline GFI & $\geq 0.90$ & .689 & .769 & Better \\
\hline AGFI & $\geq 0.90$ & 0.634 & 0.717 & Better \\
\hline TLI & $\geq 0.94$ & $0,861+)$ & $0.941 *)$ & Better \\
\hline CFI & $\geq 0.94$ & .689 & $0,769+)$ & Better \\
\hline $\operatorname{Qual} \leftarrow \operatorname{Motiv}\left(\gamma_{\mathrm{yx} 1}\right)$ & & $0.271++)$ & $\mathbf{0 , 2 8 7 + + )}$ & Better \\
\hline Qual $\leftarrow \mathbf{B U D}\left(\gamma_{\mathrm{yx} 2}\right)$ & & $0.356++)$ & $0.343++)$ & Worse \\
\hline Qual<ETHOS $\left(\gamma_{\mathrm{yx} 3}\right)$ & & $0.250++)$ & $0.251++)$ & Better \\
\hline $\operatorname{SATISFIED\leftarrow Motiv}\left(\gamma_{\mathrm{zx} 1}\right)$ & & $0.187++)$ & $0.187++)$ & Better \\
\hline SATISFIED $\leftarrow \mathbf{B U D}\left(\gamma_{\mathrm{zx} 2}\right)$ & & $0.298++)$ & $0.280++)$ & Worse \\
\hline SATISFIED $\leftarrow$ ETHOS $\left(\gamma_{Z X 3}\right)$ & & $0,302++)$ & $0.325++)$ & Better \\
\hline SATISFIED $\leftarrow Q$ Qual(Bzy) & & $0.210++)$ & $0,199++)$ & Worse \\
\hline Square Multiple Correlation Qual & & .476 & .479 & Better \\
\hline Square Multiple Correlation SATISFIED & & 0.608 & 0.602 & Worse \\
\hline
\end{tabular}

*) Fulfilling Goodness of fit

+) Marginal

$++)$ Significant

--) Not significant 
The effect of Quality of Service (Qual) variable on Merchant Satisfaction variable (SATISFIED) has regression weight of 0.210 , Critical ratio or the t-test value of 2.025 and with the probability of 0.043 . The CR value that is greater than 2.000 and the probability that is smaller than 0.05 indicate that the effect of Quality of Service (Qual) on Merchant Satisfaction (SATISFIED) is significant and positive. Based on the description above, one of the factors that affect customer satisfaction according to Lupiyoadi (2001) is product quality. A product is said to have quality if it fulfilled the expectations of customers based on the actual performance of the product.

\subsection{Model Modification}

After the modifications model processing above has been carried out, the result of processing can be seen in Fig. 3 SEM.

Modification of the model is conducted by correlating the results of several error indicators that have Modification Index (MI)> 8,000 then comparing the Goodness of Fit modification model to the modification model results. Comparisons were made including the coefficient of Goodness of Fit, Weight Regression coefficient between endogenous to exogenous variables, and Square Multiple Correlation as a reflection coefficient of determination.

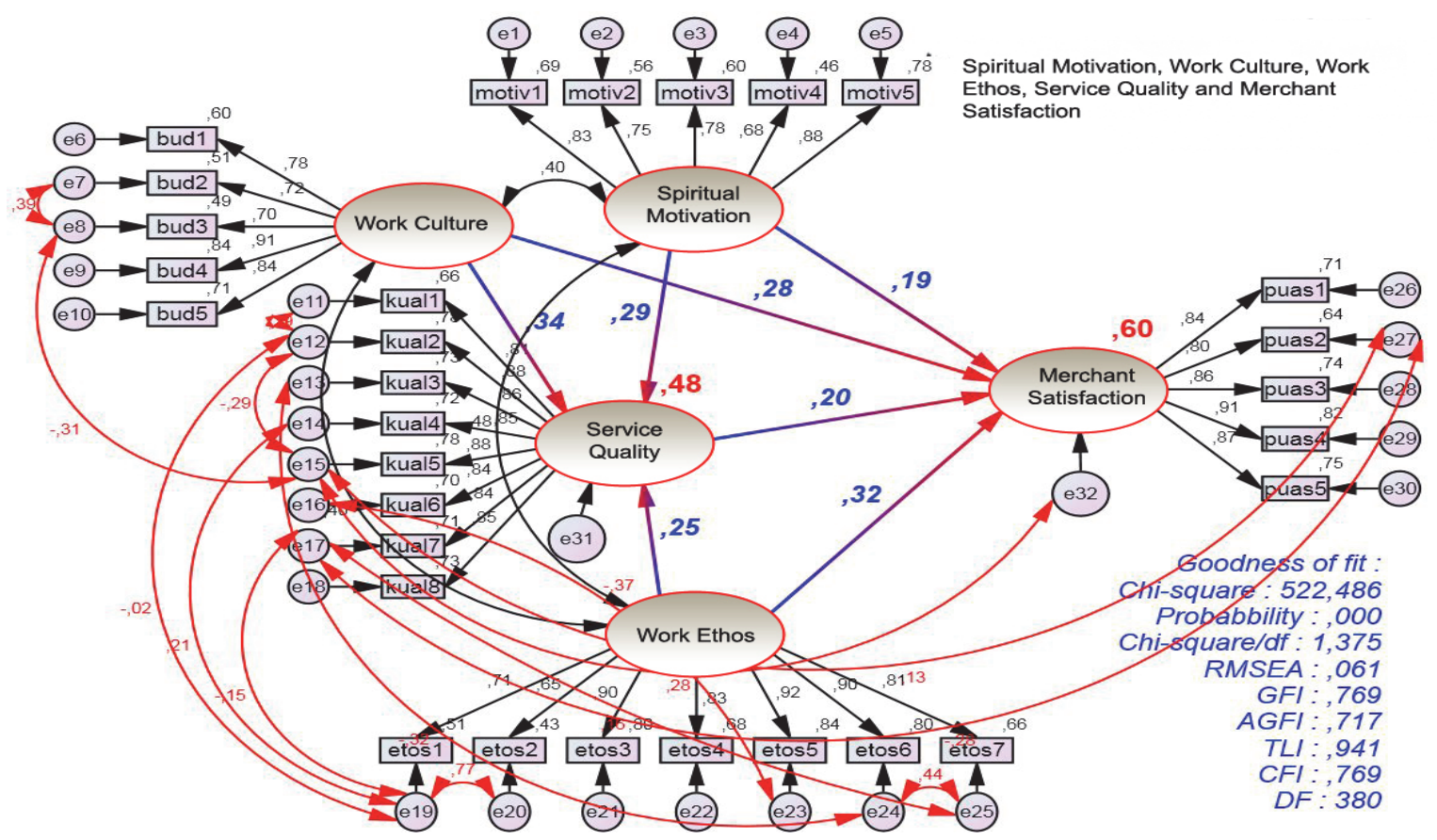

Fig. 3. Spiritual Motivation, Work Culture, Work Ethos, Service Quality and Merchant Satisfaction

Visible models modification results showed an improvement in seven indicators out of the eight indicators exists when viewed from the goodness of fit. Three indicators that qualify goodness of fit are Relative Chi-square ( $\left(\chi^{2} / \mathrm{Df}\right), \mathrm{RMSEA}$ and TLI. There is an increase in four regression coefficients (Standardized Regression Weight) and the other three declined when viewed from Regression Weight. It can be seen that there is one increase and one decline when viewed from Multiple Correlation Square. From the above analysis, it can be stated that doing the modified model could improve the suitability of the model (Goodness of fit). Due to the already existing three indicators that qualify goodness of fit, the model has been deemed appropriate.

Model modification of Regression Coefficients Variables of Spiritual Motivation, Work Culture, Work Ethos, Service Quality and Merchant Satisfaction 
The best model obtained after performing one modification, namely by correlating multiple error indicators that have Modified Index (M.I) > 8,000. Structural Equation Modeling is considered good because it has met the three criteria of eight values, namely criteria, Relative chi-square, RMSEA and TLI. The structural equations indicate that Regression Weight $(\gamma)$ of the seven variables (all variables) has significant and positive effect. This means that all the hypotheses are verified. The effect of Spiritual Motivation latent variables (Motiv) to the Service Quality latent variables (Qual) has regression weight of 0.271 , Critical ratio or the t-test value of 2.686 and with the probability of 0.007 .

The CR value that is greater than 2.000 and the probability that is smaller than 0.05 indicate that the effect of Spiritual Motivation (motive) variable on the Quality of Service (Qual) is significant and positive. The effect of work Culture latent variables (BUD) on the latent variable Quality of Service (Qual) yields the regression weight of 0.356 , the critical ratio or the t-test value 3.574 and the probability ***. The CR value that is greater than 2.000 and the probability that is smaller than 0.05 indicate that the effect of Work Culture (BUD) on the Quality of Service (Qual) is significant and positive. The effect of Work Ethic (ETHOS) on the Quality of Service (Qual) has regression weight of 0.250 , Critical ratio or the t-test value of 2.516 and with the probability of 0.012 . The CR value that is greater than 2.000 and the probability that is smaller than 0.05 indicate that the effect of Work Ethic (ETHOS) on the Quality of Service (Qual)) is significant and positive. The effect of Spiritual Motivation (motive) to the Service Quality (Qual) is positive and significant, the effect of Work Culture (BUD) to Service Quality (Qual) is positive and significant and the impact of Work Ethos (ETHOS) to the Service Quality (Qual) is positive and significant, then the simultaneous effects of Spiritual Motivation (motive), Work Culture (BUD), Work Ethos (eTHOS) to the Service Quality (Qual) are significant and positive.

The effect of Spiritual Motivation (Motiv) variable on Merchant Satisfaction latent (SATISFIED) variable has regression weight of 0.187 , Critical ratio or the t-test value of 2.190 and the probability of 0.049 . The $\mathrm{CR}$ value that is greater than 2.000 and the probability that is smaller than 0.05 indicate that the effect of Spiritual Motivation latent variables (Motiv) to Merchant Satisfaction latent variables (SATISFIED) is significant and positive. The effect of Work Culture (BUD) variable on Merchant Satisfaction (SATISFIED) variable has regression weight of 0.298 , Critical ratio or the t-test value of 3.057 and with the probability of 0.012 . The CR value that is greater than 2.000 and the probability that is smaller than 0.002 indicate that the effect of Work Culture (BUD) on Merchant Satisfaction (SATISFIED) is significant and positive. The effect of Work Ethos (ETHOS) variable on the Merchant Satisfaction (SATISFIED) variable has regression weight of 0.302 , Critical ratio or the t-test value of 3.181 and with the probability of 0.001 . The CR value that is greater than 2.000 and the probability that is smaller than 0.05 indicate that the effect of Work Ethos (ETHOS) on the Merchant Satisfaction (SATISFIED) is significant and positive. The effect of the Service Quality (Qual) variable on Merchant Satisfaction variable (SATISFIED) has regression weight of 0.210 , Critical ratio or the t-test value of 2.025 and with the probability of 0.043 . The CR value that is greater than 2.000 and the probability that is smaller than 0.05 indicate that the effect of the Service Quality (Qual) on Merchant Satisfaction (SATISFIED) is significant positive.

Square Multiple Correlation showed the value for Service Quality (Qual) is 0.476 and for Merchant Satisfaction (SATISFIED) is 0.608. According to Ferdinand, (2002: 114), the values Square Multiple Correlation to the Service Quality variables (MOT) R2 0.476 is identical with $\mathrm{R}^{2}$ in SPSS by 0.476 , Determination is the value of Square Multiple Correlation to the Service Quality variables times 100\% that is $0.476 \times 100 \%$ that equals to $47.6 \%$. The result showed that the changes in the service quality are $47.6 \%$ affected by Spiritual Motivation, Work Culture and Work Ethos. The value of Merchant Satisfaction (SATISFIED) $\mathrm{R}^{2}$ is 0.608 and the magnitude of determination is $0.608 \times 100 \%$ that equals to $60.8 \%$. Thus it can be stated that $60.8 \%$ of the Merchant Satisfaction are affected by Spiritual Motivation, Work Culture, Work Ethics, and Service Quality.

\section{Conclusion}


Due to the effect of Spiritual Motivation latent variables (motive) to the Satisfaction Merchant latent variables (SATISFIED) is significant and positive, the effect of Work Culture latent variables (BUD) to the Merchant Satisfaction latent variables (SATISFIED) is significant and positive. The effect of Work Ethos latent variables (ETHOS ) to Merchant Satisfaction latent variables (SATISFIED) is significant. Therefore, it can be stated that the effects of Spiritual Motivation (motive), Work Culture (BUD), Work Ethos (ETHOS) to Satisfaction Merchant latent variables (SATISFIED) are significant and positive. Motivation is affected by spiritual, cultural work and work ethos. Thus it can be stated that the merchant satisfaction changes are affected by spiritual motivation, work culture, work ethos and that the street vendor improve service quality. Due to the fact that the service quality is the variable between (intervening) spiritual motivation and work ethos with merchant satisfaction, it is necessary to attempt to manage service quality in order to spiritual motivation, work culture and Work Ethos contribute significantly to the Merchant Satisfaction.

\section{Suggestions}

With $76.8 \%$ to Merchant Satisfaction, there are other variables that need to be observed and implemented in order to increase Merchant Satisfaction. Local Government in order to enhance the facilities of shanties Badung Market Street Vendors and knowledge of services for merchants also need to be improved through training. To further the welfare of street vendors, local governments need to establish an institution that manages a revolving fund for cooperatives and small and medium businesses. The model of traditional markets such as the Badung Market Bali should be developed in other areas to allow the people's economy, as well as balancing the advent of modern markets in various cities.

\section{References}

Amegbe, H., Boateng, H., \& Mensah, F. (2017). Brand community integration and customer satisfaction of social media network sites among students. Management Science Letters, 7(11), 541554.

Dawi, N. M., Jusoh, A., Nor, K. M., \& Qureshi, M. I. (2016). Service Quality Dimensions in Pay TV Industry: A Preliminary Study. International Review of Management and Marketing, 6(4S).

Donald, R. C., \& Pamela, S. S. (2003). Business research methods. Tata Mac Graw Hills, New Delhi.

Ferdinand, A. (2002). Structural equation modeling in management research. Fakultas Ekonomi UNDIP: Semarang.

Hair, J. F., Black, W. C., Babin, B. J., Anderson, R. E., \& Tatham, R. L. (1998). Multivariate data analysis (Vol. 5): Prentice hall Upper Saddle River, NJ.

Koentjaraningrat, P. dr. 2004. Manusia dan Kebudayaan di Indonesia.

Nawaz, Z., Ahmad, M., Piracha, S., \& Raza, M. (2017). Customer equity of Pakistani fast food restaurant: A study of attitudinal customer equity. Management Science Letters, 7(2), 87-96.

Parasuraman, A., Zeithaml, V. A., \& Berry, L. L. (1988). Servqual: A multiple-item scale for measuring consumer perc. Journal of retailing, 64(1), 12.

Qureshi, M. I., Bashir, N., Zaman, K., Sajjad, N., \& Fakhr, S. (2012). Customer Satisfaction Measurement and Analysis using six sigma in Telecom sector of Pakistan. European Journal of Sustainable Development, 1(1), 53.

Qureshi, M. I., Khan, A., Zaman, K., \& Khaqan, N. (2014). Structural investigation of service quality in conventional and islamic banking in pakistan. International Journal of Management and Innovation, 6(1), 84.

Sekaran, U. (2000). Scientific Investigation. Research Methods for Business: A Skill Building Approach, 3, 19-35.

Shah, M. (1995). Educational psychology with a new approach. Rosdakarya, Bandung.

Sinamo, J. (2009). Etos Kerja. In.

Tasmara, T. (2002). Cultivating Islamic Work Ethics. In: Jakarta: Gema Insani Press. 
(C) 2018 by the authors; licensee Growing Science, Canada. This is an open access article distributed under the terms and conditions of the Creative Commons Attribution (CC-BY) license (http://creativecommons.org/licenses/by/4.0/). 